\title{
STUDI PERBANDINGAN GEDUNG TAHAN GEMPA MENGGUNAKAN SNI 03- 1726-2002 DAN SNI 1726-2012
}

\author{
Muhammad Faiz \\ Program Studi Teknik Sipil Universitas Muhammadiyah Sorong \\ Jalan Pendidikan No 27 Kota Sorong, Propinsi Papua Barat \\ Email :faizm9900@gmail.com
}

\begin{abstract}
ABSTRAK
Indonesia sering dikejutkan dengan berbagai macam bencana alam, terutama gempa. Hal ini terjadi karena Indonesia berada di kawasan Pasific Ring Of Fire. Kedatangan gempa tidak dapat diprediksi secara pasti tempat dan waktunya, oleh sebab itu, harus ada sistem pemberitahuan dini terhadap bahaya gempa dan pengantisipasian dengan pembangunan gedung tahan gempa agar tidak memakan korban jiwa. Di Indonesia terdapat standar kegempaan SNI 03-1726-2002. Akan tetapi menurut para ahli gempa di Indonesia, peraturan ini dirasa sudah tidak sesuai lagi diaplikasikan sebagai pedoman perencanaan struktur tahan gempa karena mengingat pada waktu gempa besar terjadi masih terjadi kerusakan pada struktur bangunan. Seiring berjalannya waktu dan teknologi, maka dilakukan pembaharuan dengan disusunnya SNI 03-1726-2012 sebagai standar kegempaan yang baru. Dengan adanya SNI 03-1726-2012 maka dilakukan analisis perbandingan seberapa besar perubahannya dari standar kegempaan yang lama. Agar bisa mengetahui seberapa efektif dalam penggunaan standar tersebut pada perencanaan gedung tahan gempa. Tujuan dari penulisan tugas akhir ini adalah untuk mengetahui perbedaan beban gempa antara SNI 2002 dengan SNI 2012 berdasarkan displacement,drift ratio,dan base shear, mengetahui perbedaan hasil analisis gempa dinamis linier antara SNI 2002 dengan SNI 2012. Proses analisis menggunakan model gedung 10 lantai untuk analisis gempa dinamis linier. Zona wilayah gempa adalah zona kota Sorong dengan jenis tanah Lunak.
\end{abstract}

Kata Kunci : SNI 03-1726-2002, SNI 03-1726-2012, displacement. 
PENDAHULUAN

\section{Latar Belakang}

Sorong merupakan salah satu kota yang terletak di Provinsi Papua Barat. Daerah ini memiliki tingkat kerentanan yang tinggi terhadap ancaman bahaya gempa bumi karena lokasinya terletak di antara pertemuan lempengan tektonik dan beberapa sesar aktif. Pada tahun 2015 terjadi gempa bumi di Kota Sorong dengan kekuatan 6,8 Skala Richter yang berpusat di laut berjarak 31 kilometer Timur Laut Kota Sorong, Papua Barat dengan kedalaman gempa 10 kilometer. Dalam skala Modified Mercalli Intencity (MMI) gempa tersebut masuk dalam kategori gempa dengan intensitas V MMI sehingga dikategorikan sebagai gempa yang merusak (Wikipedia). Gempa ini mengakibatkan banyaknya bangunan yang runtuh di Kota Sorong dan banyak pula korban dengan luka berat maupun ringan akibat runtuhnya bangunan. Runtuhnya bangunan dapat diminimalisir dengan menganalisa permodelan gedung pada saat terjadi gempa sehingga perencana dapat lebih baik dalam merencanakan gedung yang akan dibuat. Pengaruh gaya gempa akan berbeda jika diaplikasikan terhadap bangunan beraturan dan tidak beraturan. Kinerja struktur yang dihasilkan untuk gedung tidak beraturan akan berbeda dengan gedung beraturan untuk intensitas beban yang sama, misalnya jika dibandingkan terhadap simpangan (displacement), simpangan antar lantai (drift), dan penulangannya.

\section{Tujuan Penelitian}

Tujuan dari penelitian ini adalah mengetahui perbedaan perencanaan struktur gedung sesuai hasil analisis hitungan berdasarkan SNI 03-1726-2002 dan SNI 1726-2012 yang berlokasi di wilayah Kota Sorong.

\section{STATE OF THE ART}

Adapun penelitian terdahulu yang terkait dengan penelitian ini adalah sebagai berikut :

1. Menurut Yoyong dan Iman (2013) menyebutkan bahwa Pada penelitian terdahulu, perubahan respons spektra SNI 03-1726-2012 bergantung pada pergerakan wilayah kegempaan dari tahun 2002 ke 2012 pada daerah tersebut. Sehingga pergerakan tanah ini, menjadi faktor perubahan nilai respons spektra pada SNI yang baru. Pembagian wilayah gempa berdasarkan SNI 03-1726-2002 tidak menjadi patokan untuk perubahan respons spektra SNI 03-1726-2012. Tidak selalu wilayah kegempaan dengan gempa tinggi pada SNI 03-1726-2012 mengalami kenaikan pada respons spektranya. Begitu juga pada wilayah kegempaan dengan gempa yang rendah.

2. Menurut Lailasari (2014) menyebutkan Kekurangan dari SNI 03-1726-2002 yaitu pada pembagian wilayah kegempaan-nya. Di dalam zona gempa SNI 2002 mengganggap semua daerah di setiap kota memiliki respons spektra yang sama. Tetapi pada kenyataannya setiap daerah atau dalam lingkup yang kecil misalnya setiap kecamatan pada suatu kabupaten tidak memiliki respons spektra yang sama. Kekurangan ini menjadi kelebihan dari SNI 03-1726-2012 sebagai standar kegempaan yang telah diperbaharui.

3. Menurut Purnomo (2014) Analisis dinamik untuk perancangan struktur tahan gempa dilakukan jika diperlukan evaluasi yang lebih akurat terhadap gaya-gaya gempa yang bekerja pada struktur, serta untuk mengetahui perilaku dari struktur akibat pengaruh gempa. Analisis dinamik dilakukan pada perancangan struktur bangunan tingkat tinggi atau struktur dengan bentuk atau konfigurasi yang tidak teratur. Analisis dinamik dapat dilakukan dengan cara elastis maupun inelastis. Pada cara elastis dibedakan menjadi Analisis Ragam Riwayat Waktu(Time History Modal Analysis),dimana pada cara ini diperlukan rekaman percepatan gempa dan Analisis Ragam Spektrum Respon(Respons Spectrum Modal Analysis), dimana pada cara ini respon maksimum dari tiap ragam getar yang terjadi didapat dari Spektrum Respon Rencana (Design Spectra).

4. Menurut Soelarso (2016) Untuk menganalisis sebuah gedung hal pertama yang perlu direncanakan adalah menentukan model gedung dan tipe pemangku yang digunakan. Tugas akhir ini membandingkan hasil simpangan yang terjadi dengan VBracing, dan Inverted V-Bracing serta membandingkan hasil simpangan akibat gempa dari SNI 1726-2002 dengan SNI 1726-2012. Untuk analisa gedung menggunakan program ETABS v.9.0.

5. Menurut Setiawan (2017) Seiring dengan perkembangan yang ada, standar untuk perencanaan gedung tahan gempa perlu diperbaharui, dikembangkan dan disesuaikan dengan keadaan yang terjadi. Desain bangunan tahan gempa di Indonesia menggunakan acuan Standar Nasional Indonesia, yaitu Tata Cara Perencanaan Ketahanan Gempa Untuk Struktur Bangunan Gedung dan Non gedung SNI 03-1726-2002 yang telah diperbaharui menjadi SNI 03-1726-2012. 


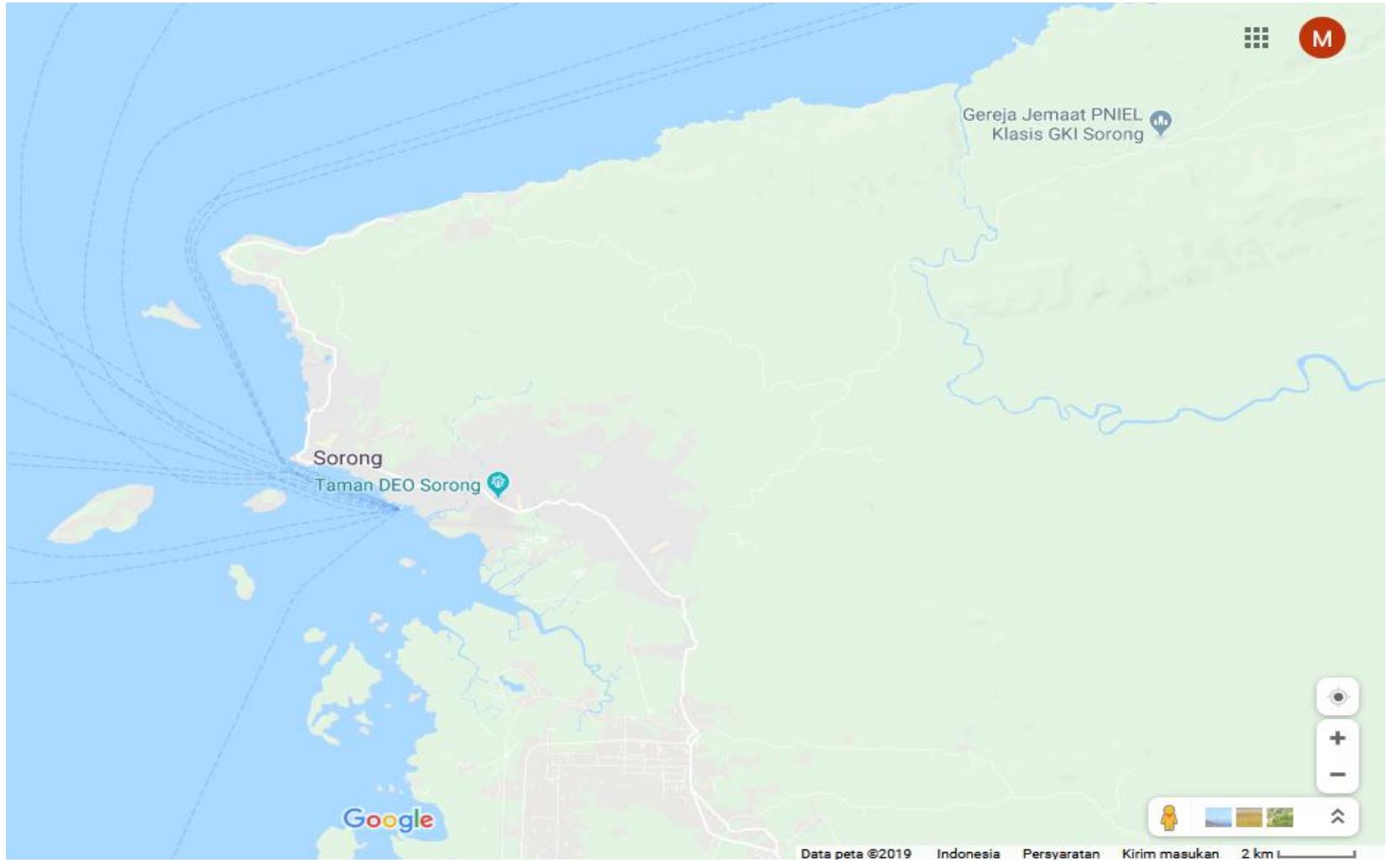

Tahapan penelitian yang digunakan adalah sebagai berikut :

1. Melakukan pengumpulan data perencanaan permodelan gedung 10 lantai.

2. Permodelan dan pembebanan struktur dengan software SAP 2000 .

3. Menganalisa ragam respon spektra model gedung 10 lantai dengan SNI 03-1726-2002 dan SNI 03-1726-2012.

4. Proses analisis dan perbandingan setelah itu membuat kesimpulan.

Semua metode penulisan dan analisa dalam artikel ilmiah ini merujuk pada panduan penulisan tugas akhir Fakultas Teknik Universitas Muhammadiyah Sorong tahun 2014 (Pristianto, Amri, \& Rusdi, 2014).

\section{REFERENSI}

1. Lailasari, D., Wibowo, A., \& Nuralinah, D. (2014). STUDI KOMPARASI PERENCANAAN GEDUNG TAHAN GEMPA DENGAN MENGGUNAKAN SNI 03-1726-2002 DAN SNI 03-1726-2012.

2. Purnomo, E.,Purwanto, E.,Supriyadi, A. (2014) . ANALISIS KINERJA STRUKTUR PADA GEDUNG BERTINGKAT DENGAN ANALISIS DINAMIK RESPON SPEKTRUM MENGGUNAKAN SOFTWARE ETABS (STUDI KASUS : BANGUNAN HOTEL DI SEMARANG).

3. Soelarso., Baehaki., Novtikania, F. (2016). ANALISIS PERBANDINGAN SIMPANGAN HORISONTAL (DRIFT) PADA STRUKTUR GEDUNG TAHAN GEMPA DENGAN MENGGUNAKAN PENGAKU LATERAL (BRACING) BERDASARKAN SNI 03-1726-2002 DAN SNI 03-1726-2012. (Jurnal Fondasi, Volume 5 No 1)

4. Setiawan, H M. (2017). EVALUASI PERBANDINGAN DESAIN STRUKTUR BETON BERTULANG GEDUNG 10 LANTAI YANG DIDESAIN BERDASARKAN SNI 03-1726-2002 DAN SNI 03-1726-2012. 
5. Yoyong \& Iman (2013). PERBANDINGAN SPEKTRA DESAIN BEBERAPA KOTA BESAR DI INDONESIA DALAM SNI GEMPA 2012 DAN SNI GEMPA 2002.

6. Pristianto, H., Amri, I., \& Rusdi, A. (2014, May 9). Pedoman Penulisan Tugas Akhir Fakultas Teknik Universitas Muhammadiyah Sorong 2014. http://doi.org/10.17605/OSF.IO/4VTJM. 